\title{
DETERMINATION OF SEGMENTED ANGULAR SHAPES FOR CIRCULAR AREAS OF THERMAL EQUIPMENT
}

\author{
J.K. Nsiah \\ Department of Industrial Art, \\ College of Art and Social Sciences, \\ Kwame Nkrumah University of Science and Technology, Kumasi, Ghana
}

\begin{abstract}
Most thermal equipment like industrial boilers, ceramic kilns, incinerators, thermal plants for electricity generation, have specially designed circular areas through which heat passes or generates. Since these areas are circular in design, fabrication and lining with refractory materials present technical problems that must be understood. Moreover, angular shapes that are required to construct circular areas are not readily available for procurement. These segmented angular shapes are not standardized, so depending on the make of the thermal equipment, suitable segments must be fabricated to fit. Moulds have to be fabricated and shapes cast out, using high temperature castables. These intricate procedures for the design and construction of circular segmented angular shapes have been, exhaustively, treated in this paper.
\end{abstract}

Keywords: thermal equipment, neck, segmented angular shapes, castables, and high temperature refractory

\section{INTRODUCTION}

It is not easy to get ready-made shapes that are needed for the construction of refractory areas of round necks of boilers, round furnaces, round ceramic kilns, electric generation plants, and burner areas of gas or oil boilers. This is more so when particular shapes may not be suitable for one's own designs. Making and fixing of such shapes present some technical problems.

These circular areas of thermal equipment are very critical because they are heat generation areas; they also serve as passage for generated heat. Boilers, for example, are pressure vessels, in which water at room temperature $\left(23^{\circ} \mathrm{C}\right)$ is heated, up to and beyond its boiling point $\left(100^{\circ} \mathrm{C}\right)$ (Vincenzini,1991), for the generation of hot water, steam and super steam for industrial processes like drying of lumber, pressing of plywood, generation of electricity, food processing.

Kilns are equipment used for the firing of ceramic products. Furnaces are specially constructed chambers built with refractory bricks and other heat resistant materials, in which fuel is combusted to provide heat energy for industrial processes. Of the equipment described, the necks of boiler furnaces require frequent replacement. The necks, which are made of refractory materials, are replaced every one to three years of operation, depending upon factors like quality of the refractory castable and 
more importantly the action of heat on refractory material used (Anthony and Harry, 1991). Any company that has only one boiler has to stop operation during the period of mould maintenance, casting, drying and fixing. This takes up to one week, causing financial losses. For those companies that have more boilers working at the same time, a breakdown of one of them would mean a reduction in production levels. However, other companies (very few) have standby boilers and can easily switch on to another during period of replacement.

The damaged ceramic material, which needs replacement, is caused by the following:

- The corrosive action of the combustion products like sulphur dioxide on the material at the neck area

- Damage suffered from the continuous impingement of heat on the refractory materials and the all-year-round use of the equipment

- The frequent shuttingdown of the equipment (once or twice a week for two to six hours) for cleaning. This results in sudden expansion and contraction of materials, resulting in formation of cracks and eventually of the failure of the material.

- The type of fuel used by the equipment. For example, a fuel like ciber used in the timber industry is a low fluxing material and therefore has a low melting point. It easily melts, and when mixed with ashes, forms a glassy layer, which sticks onto the refractory material when the equipment is shut down for cleaning. Removing this glassy layer, during cleaning, results in loss of refractory material. Over a long period, the neck material, which would wear off, should be replaced.

In the case of industrial boiler necks, for example, heat passes through the neck from the furnace into the main shell, which has an assemblage of special seamless tubes or pipes of varying sizes.

Round shapes are very effective heat generation and transmission equipment and it is therefore important that the concept is fully understood. Once the concept is understood, two issues are at stake.

- Either ready-moulded bricks are cut to shape and size using diamond blade brick cutting machine or

- That the precise or required shapes are cast from moulds, using high density or lightweight castables.

However, cutting of ready-moulded bricks has some limiting factors such as availability of a cutting machine and obtaining the needed precision of the angular shapes. Thus, angular shapes are best obtained using moulds.

A castable is a specially formulated refractory material (Dinsdale, 1986), which has varying particle size distributions that crystallize into a hard mass, as hard as a brick, with strength of about $35 \mathrm{MPa}$ (Ceramic Research Centre, 2000), when mixed with the correct amount of water (at room temperature). Like heat resistant bricks or other refractory materials, these castables protect the metal parts of equipment or machines from burning or deforming, and to prevent heat losses. Imported castables often have labels describing the materials and the water-mixing ratio per $25 \mathrm{~kg}$ standard bag. The high temperature castables (high density types) range from $1300{ }^{\circ} \mathrm{C}-1820^{\circ} \mathrm{C}$. The lightweight castable, is normally fired below $1100{ }^{\circ} \mathrm{C}$. For this reason, it is used mainly for insulation, and for areas where temperatures are not high, e.g. boiler doors, etc.

Another component of the cast segment is the ceramic fibre. This is an inorganic heat insulating material used to prevent heat loss in thermal equipment. Ceramic fibre comes in three forms. These are Alumina-silica fibre, Alumina fibre and Silica fibre. The type referred to in this paper is the Alumina-silica fibre. Aluminasilica fibre is a glassy fibre made from $\mathrm{Al}_{2} \mathrm{O}_{3}$ $\mathrm{SiO}_{2}$ series of materials. In the past, kaolin, kyanite and other similar materials were melted in an electric arc furnace or reverberatory furnace to make them fibrous. However, because of the impurities such as $\mathrm{Na}_{2} \mathrm{O}, \mathrm{Fe}_{2} \mathrm{O}_{3}$, which have low melting compositions, highly pure 
chemically refined materials are applied. The main functions of any ceramic fibre are to prevent heat loss from the equipment, to absorb heat, and to absorb thermal expansion of the refractory materials.

\section{PROCEDURE}

Steps for forming segments for circular shapes

The actual dimension of the circular shape is taken and the radius, $\mathrm{R}$, is copied on plywood or drawn to scale on a drawing paper. In the case of the former, which is the common practice, two nails are fixed on a wood plank with the distance between them being the radius, $\mathrm{R}$ of the circular shape (Fig. 1).

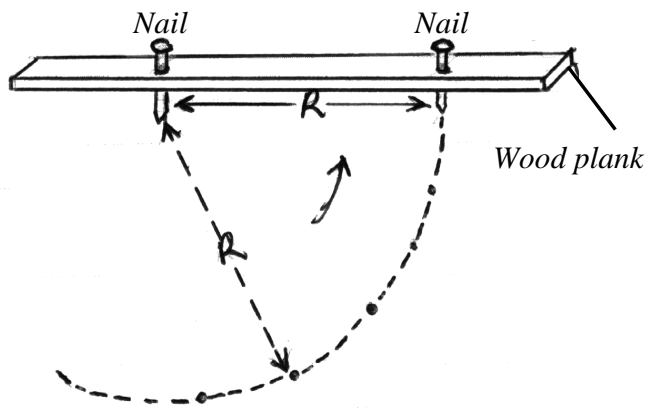

Fig. 1: Drawing a circle with a wood plank

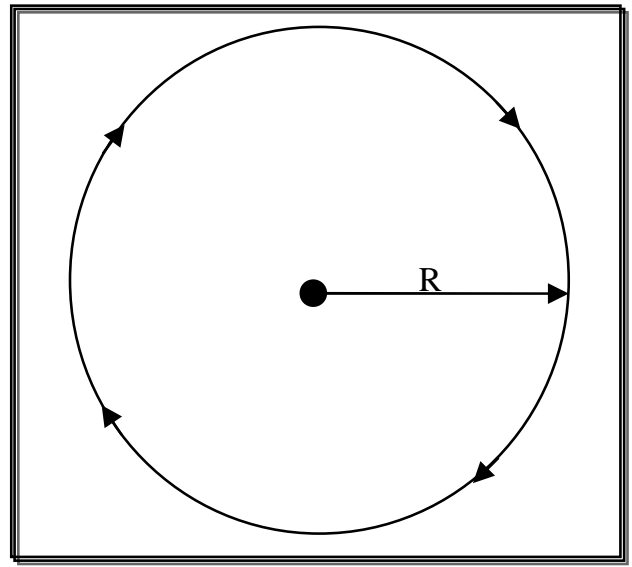

Fig. 2: Circle marked after one revolution of the wood plank
One of the nails is fixed at the centre, $\mathrm{O}$, and the other nail is rotated through one revolution, at a constant distance of $\mathrm{R}$, to mark the circle on a $0.3 \mathrm{~cm}$ thick plywood as shown in Fig. 2 .

The circle is segmented into four equal parts (Fig. 3) as follows:

- Draw line $\mathrm{AB}=$ diameter

- Mark the center O

- Mark equal points $\mathrm{C}$ and $\mathrm{D} ; \mathrm{CO}=\mathrm{DO}$

- With a compass draw two arcs to bisect at $\mathrm{X}_{-1}, \mathrm{X}_{-2}$

- Draw E, F through the central points of $\mathrm{X}_{-1}$, $\mathrm{X}_{-2}$; the circle is divided into four equal parts

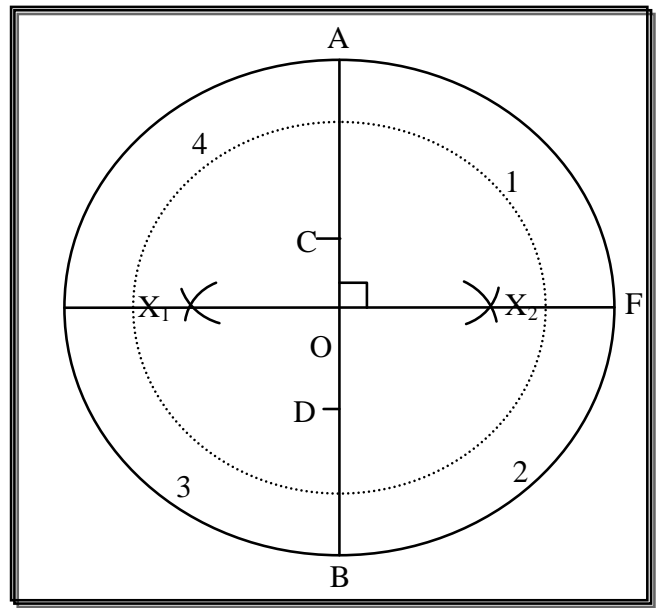

Fig. 3: Circle divided into four equal parts $1=2=3=4$

Draw the thickness of the segment or brick as shown by the dotted circle. Label parts 1, 2, 3, 4. The size of the segment depends upon one's design or the existing shape being copied. The number of segment will depend on the overall size and weight of the part to be fabricated. In this case, the original drawings, if they are available, are necessary guidelines. Depending on the what size is to be produced, the circle could be divided into eight equal parts by dividing the $90^{\circ}$ angles into two equal parts, or $45^{\circ}$ angle each, with a protractor or twelve equal parts is obtained by dividing the $90^{\circ}$ angles into 


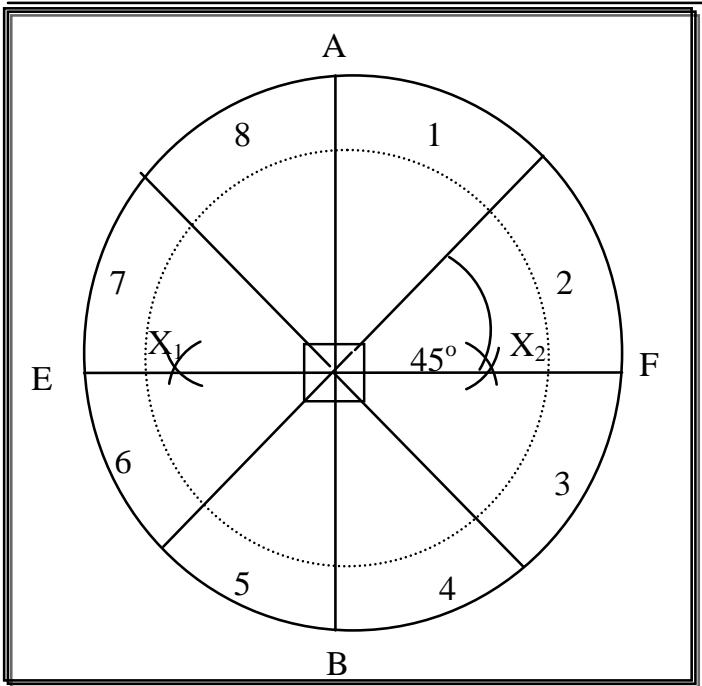

$$
1=2=3=4=5=6=7=8
$$

Fig. 4: Circle divided into eight segments

three equal parts i.e. $30^{\circ}$ each. These additional segmentations are illustrated by figures 4 and 5 respectively.

These are the required and precise angular shapes for the two circles. Once the sizes have been known, a brick-cutting machine, fitted with a diamond cutter, can be used to cut out the shapes or the shapes can be cast out of a mould that can be made. Different moulds are needed for different circular areas, depending on their sizes - usually these moulds are custom made.

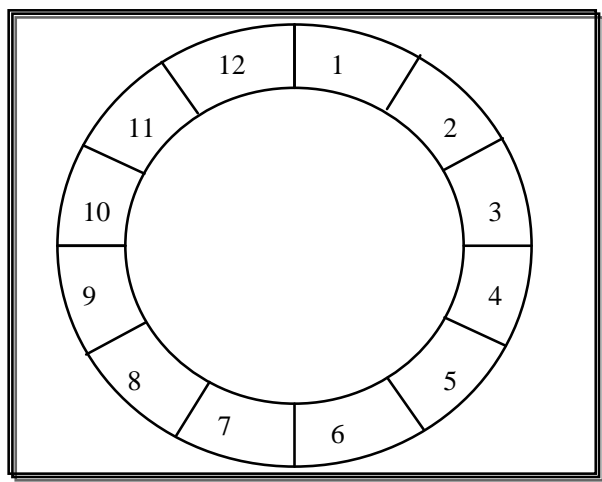

Fig. 6: 12 Segmented angular parts mark wooden platform

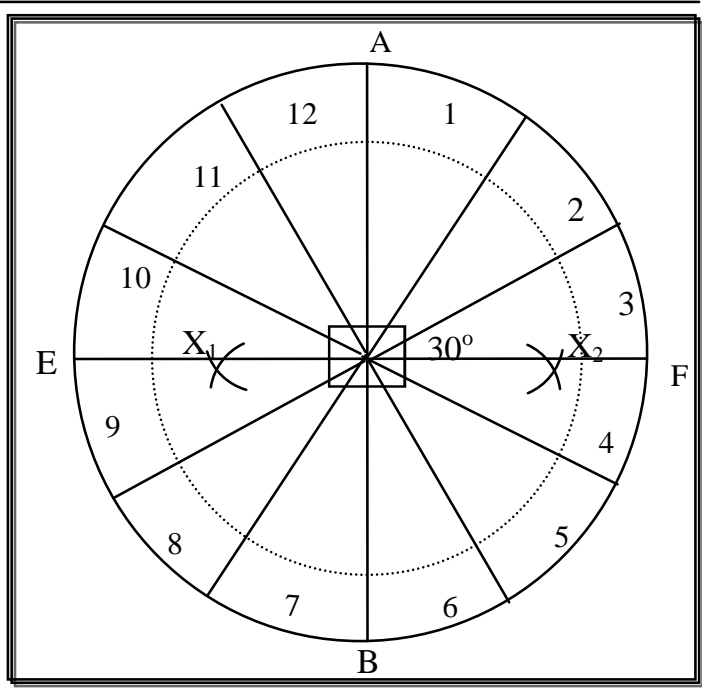

$$
1=2=3=4=5=6=7=8=9=10=11=12
$$

Fig. 5: Circle divided into twelve segments

FABRICATION OF MOULDS FOR CASTING OF CIRCULAR PARTS

Making wooden moulds is a bit of a task. Sometimes metallic moulds may be used.

Using the 12-segmented parts, as an example, first mark out the segments on the flat solid board, of reasonable thickness e.g. $5.0 \mathrm{~cm}$, as shown in figure 6 . The wooden flat board is split into two parts G \& H (Figure 7), using an ordinary saw or a bandsaw. The middle portions I and $\mathrm{J}$, are sawn out.
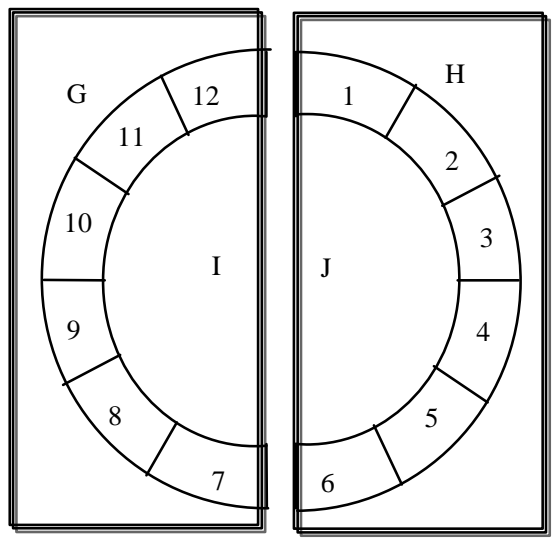

Fig. 7: Splitted wooden platform

66 Journal of Science and Technology, Vol. 29, No. 2, Aug., 2009 


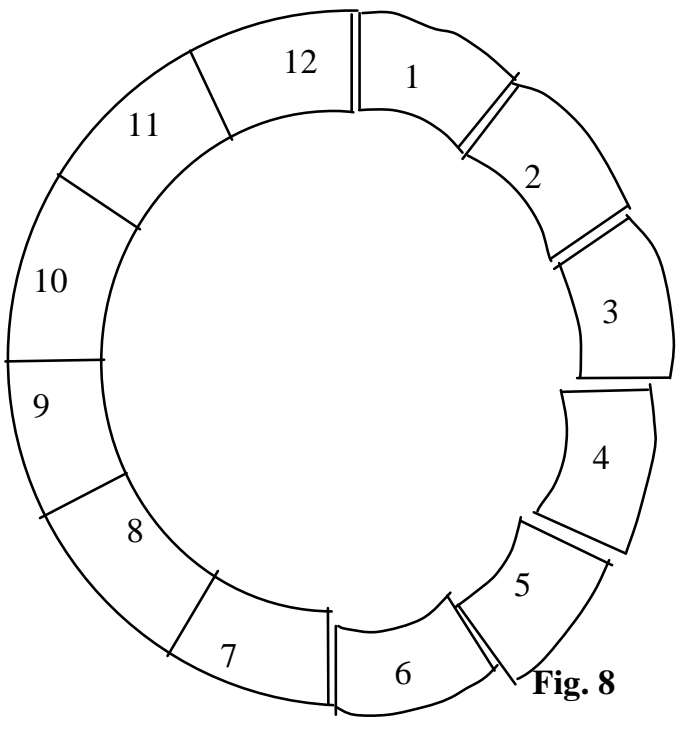

The demarcated segments and the central portions, I and J, are sawn out of the plywood. The segmented section is then sawn into 12 segments as shown in figure 8 and used as a template. Figure 9 is I and $\mathbf{J}$ of the central portion. Two pieces of each segment is cut out from a $2.5 \mathrm{~cm}$ wawa board.

The two inner halves, I \& J, are used as template for obtaining similar halves from a $2.5 \mathrm{~cm}$ Wawa board. They are used for the construc-

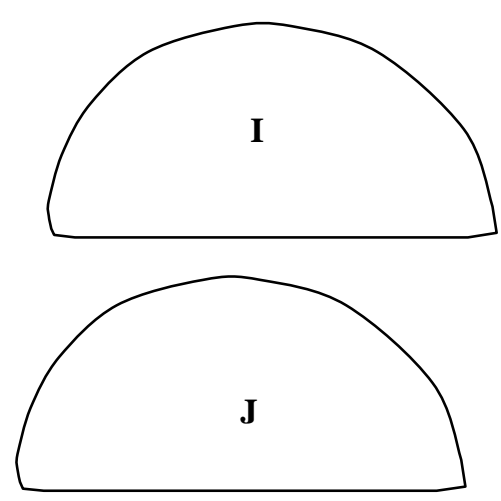

Fig. $9 \quad I=J$

tion of a frame for the whole segment. These frames would be necessary when it comes to fixing the shaped bricks or cast segmented angular shapes in the equipment.

The moulds are fabricated using the two pieces of each segment reinforced by pieces of wood serving as the sides of the mould depending on the length of the segment, and a $0.3 \mathrm{~cm}$ plywood as the base. In this case, there are 12 moulds, of equal measurement, to be made. The pieces for the segments and the transitional pieces are cut from a $2.5 \mathrm{~cm}$ wawa board. It is important to
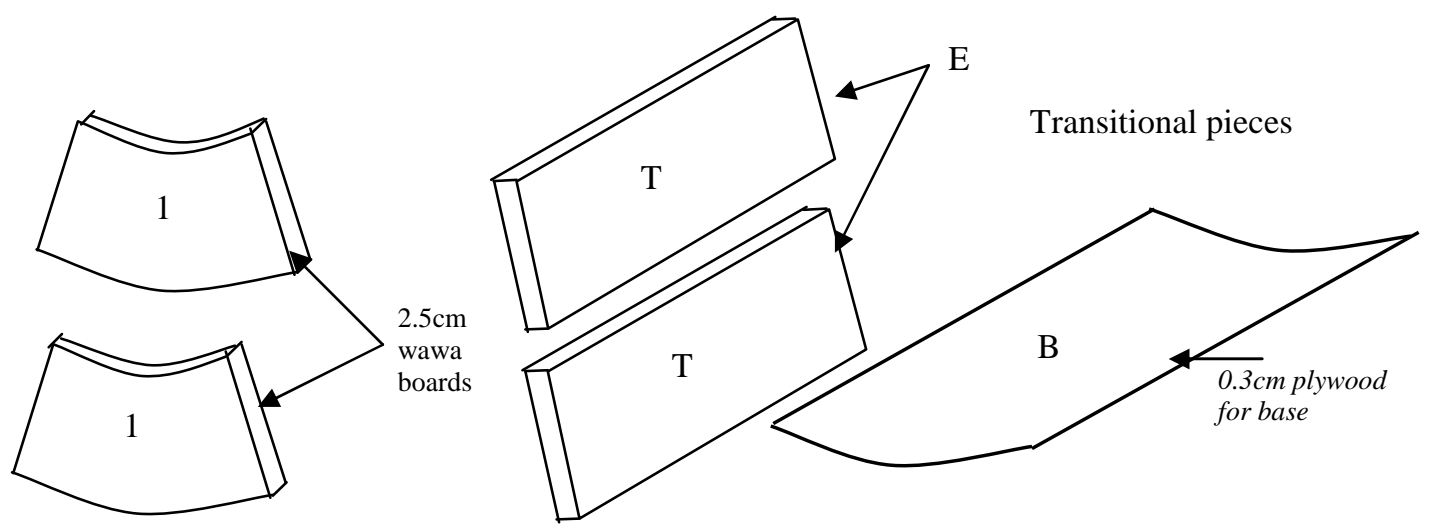

Fig. 10: Pieces required to assemble into mould - 1-1 two samples of segment 1; T-T the transitional pieces; $B$ represents the base plywood 
The essembled mould is shown in Fig. 11and Fig. 12
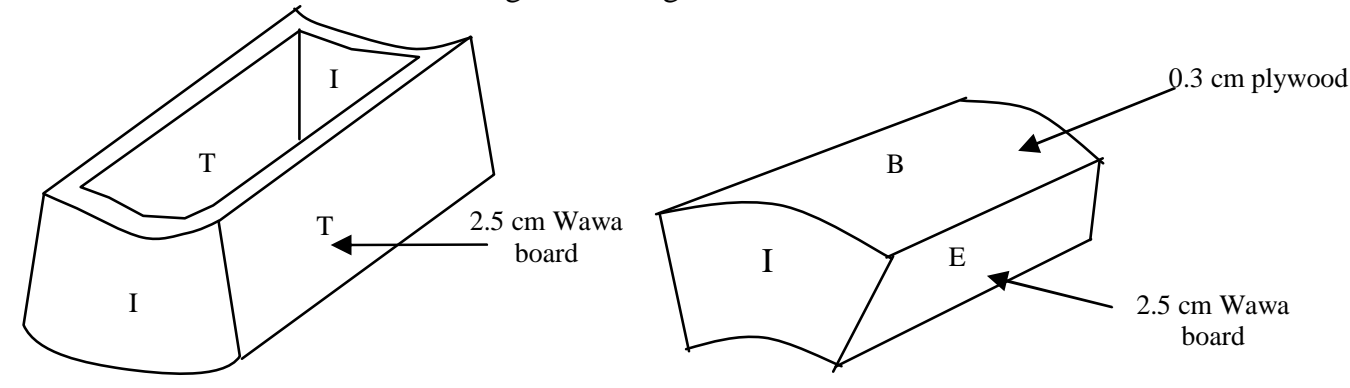

Fig. 12: Assembled mould turned upside down

note that the inner dimensions of the moulds are the actual size of the segments. Figure 10 shows the pieces required to assemble the mould.

\section{CASTING THE SHAPES}

After oaking the moulds, they are assembled and checked and corrections made. The next stage is to cast the required shapes out of them. Depending upon the temperature requirements and the areas that the segments are going to be

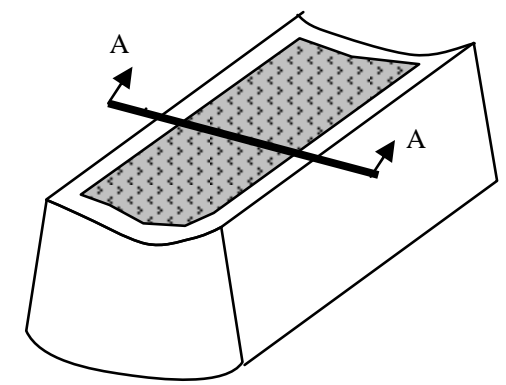

Fig. 13: Mould filled with castable

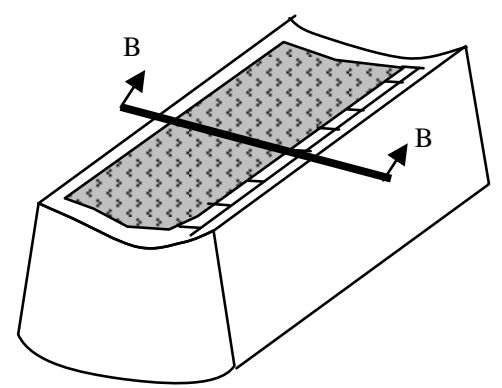

fixed, either lightweight or high density castable can be used.

Before casting, all the moulds must be numbered. High temperature ceramic fibre is used either at the sides of some segments or at the base of the segments or at both the base and side of some segments to reduce the effect of thermal expansion during service. Figure 13 illustrates a mould filled with castable, without a ceramic fibre. Figures 14, depicts how ceramic fibre is used to compensate for expansion

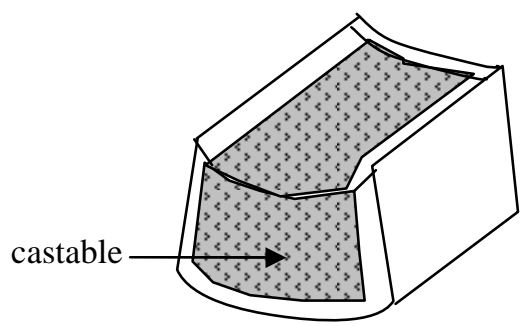

Section A-A

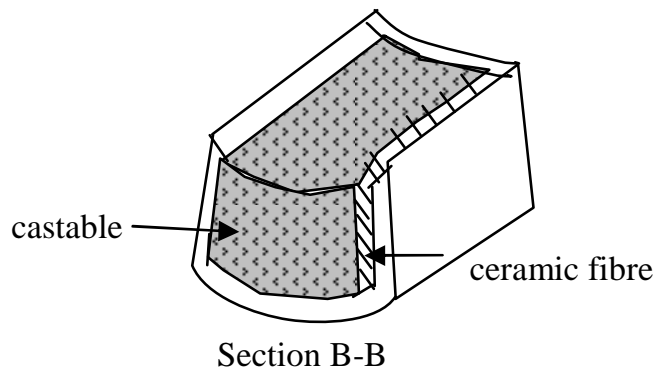

Section B-B

Fig. 14: Mould filled with castable and ceramic fibre at one side

68 Journal of Science and Technology, Vol. 29, No. 2, Aug., 2009 


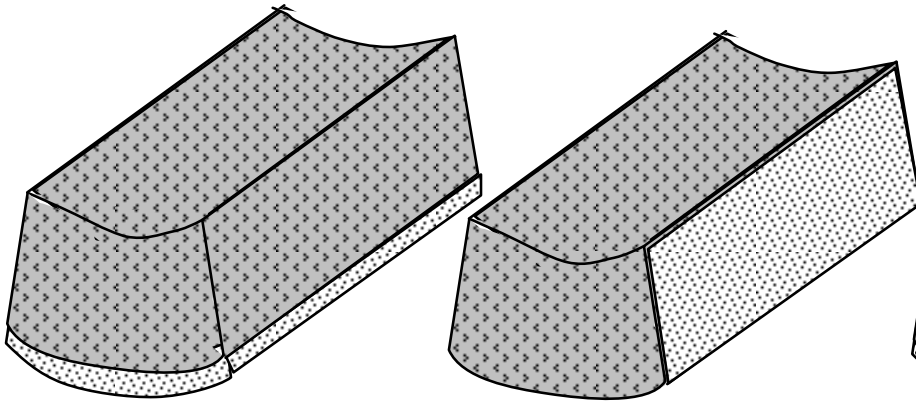

(a) Cast with ceramic fibre at base (b) Cast with ceramic fibre at side

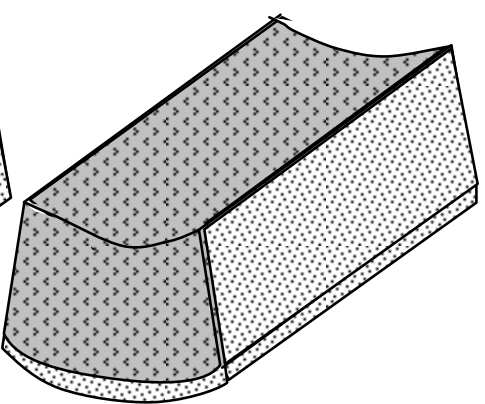

(c) Cast with ceramic fibre at side and base

Fig. 15: Dried cast segments removed from moulds

Figures 15 depicts dried cast segments removed from their moulds. For easy and precise fixing, the removed segments should be numbered according to the numbers on the moulds.

Figure 15a,b\&c are casts with ceramic fibre at different sides.

\section{FABRICATION OF THE FRAME}

The frame, Fig 16a, is fabricated using the two $2.5 \mathrm{~cm}$ inner portions (figure 9), i.e. portions I $\&$ J. For easy removal of the frame from the fixed segments after fixing, it is better to reduce the lower part of the semi-circular wawa board, by $5 \mathrm{~cm}$ (two inches), as shown in figure $16 \mathrm{~b}$.

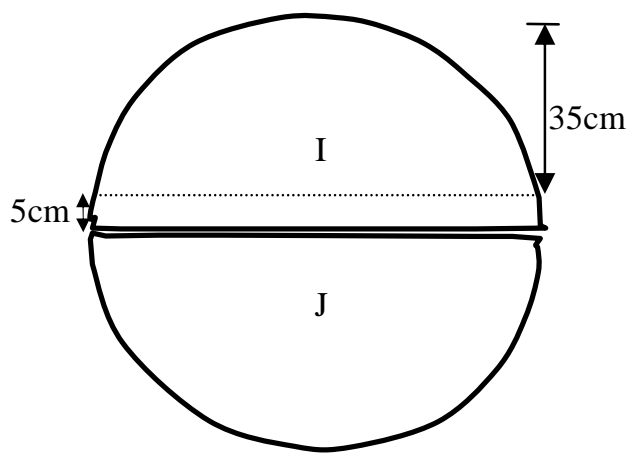

(a) Two semi-circular pieces used for frame construction
The procedure for making the frame is as follows:

Join the two semi-circular shapes I and J, with a $2.5 \mathrm{~cm} \times 2.5 \mathrm{~cm}$ 'wawa' battens. The top is then covered with $0.3 \mathrm{~cm}$ plywood. The fabricated frame takes the form of figure 17.

\section{ARRANGING THE CAST SEGMENTS}

After the fabrication of the frame, the cast segments are arranged vertically, in numerical order, on a clean floor or on a plywood and checked whether the dimensions are correct, and that the segments together will fit in the circular section of the equipment. Figure 19 illustrates this arrangement.

It is important to try the frame inside the arranged segments to check the fitness.

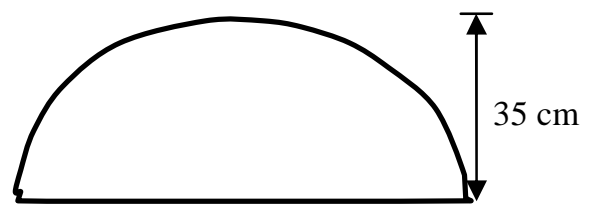

(b) Sample of semi-circular piece reduced by $5 \mathrm{~cm}$

Fig. 16: The central portion of the segmented board for frame construction 


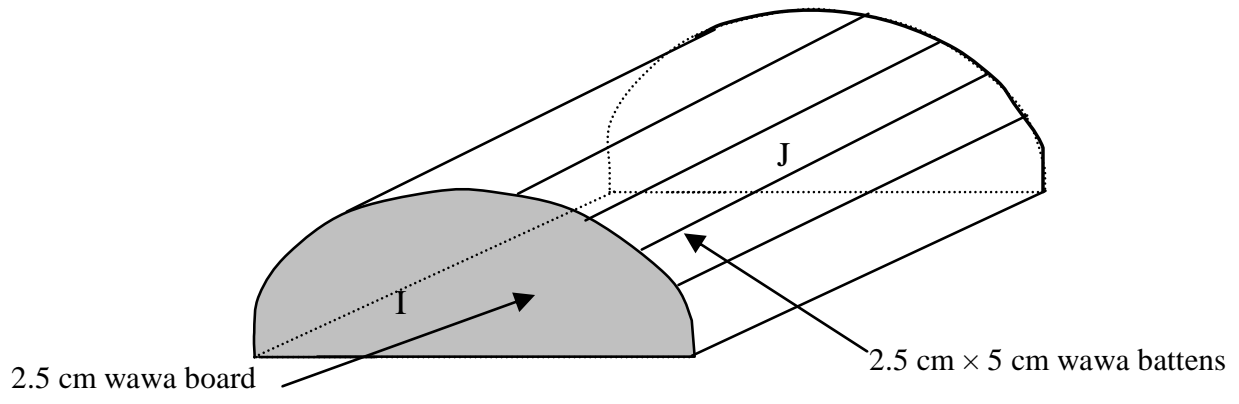

Fig. 17: Semi-circular pieces joined by battens

Figure 18 shows the frame covered with a $0.3 \mathrm{~cm}$ plywood.

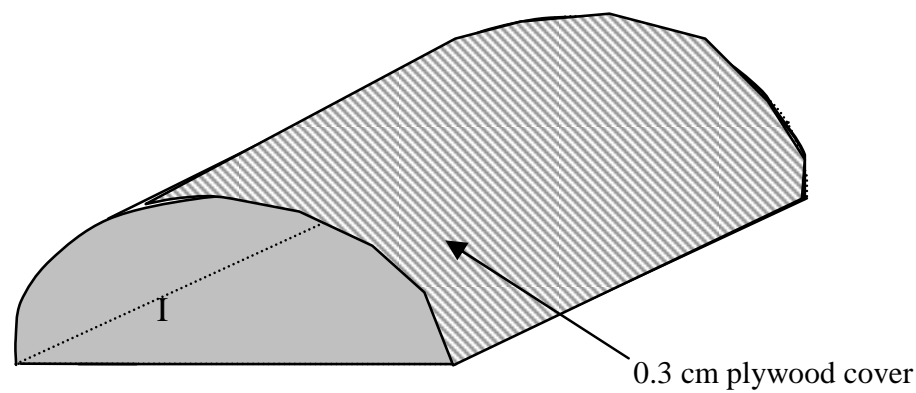

Fig. 18: Finished frame, with plywood cover

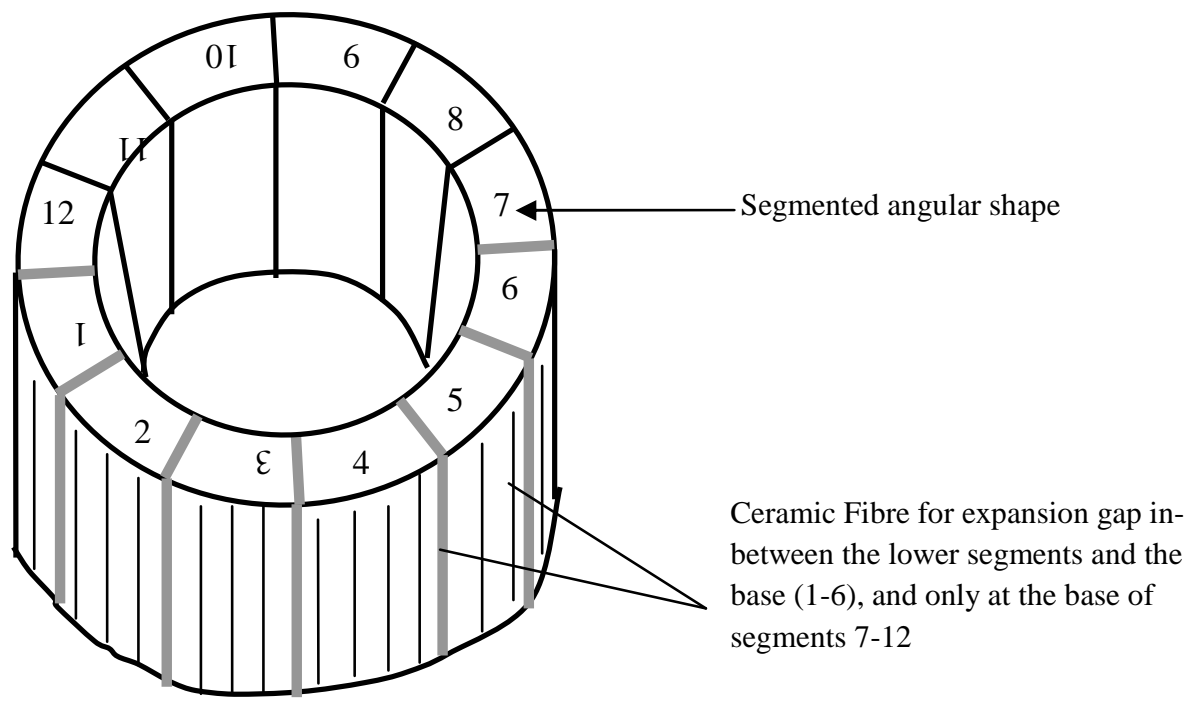

Fig. 19: Arrangement of cast segments on a floor or plywood

70 Journal of Science and Technology, Vol. 29, No. 2, Aug., 2009 
It should be noted that when fixing the cast segments, there must not be any ceramic fibre in-between the segments in the top zone, i.e. segments 7-12. This is because the action of draft will gradually blow it off resulting in the segment(s) dropping. Moreover, the effect of some combustion products on the top zone could destroy the fibre, and eventually cause sine some egmebt to some segment(s) to fall off.

\section{FIXING THE SEGMENTS}

When the segments are found to fit correctly, they are then fixed starting with the segment numbered 3 from the left, i.e. $180^{\circ}$ from the North-South line. For horizontal fixing ar- rangements of shapes, it is easy and there is no need of a frame. For vertical ones, however, it is unnerving.

The procedure for fixing the cast pieces of the latter is, as follows:

- The lower (segments) section is first arranged. The step-to-step procedure is illustrated by the figures below.

As can be seen from the drawings below, No. 3 is fixed first (fig. 20a). Then followed by No. 4 , then No. 2, No. 5, (fig. 20b). Finally, No. 1 and No. 6 are fixed, to complete the lower segment (fig. 20c). Refractory mortar is used to bind the segments together.
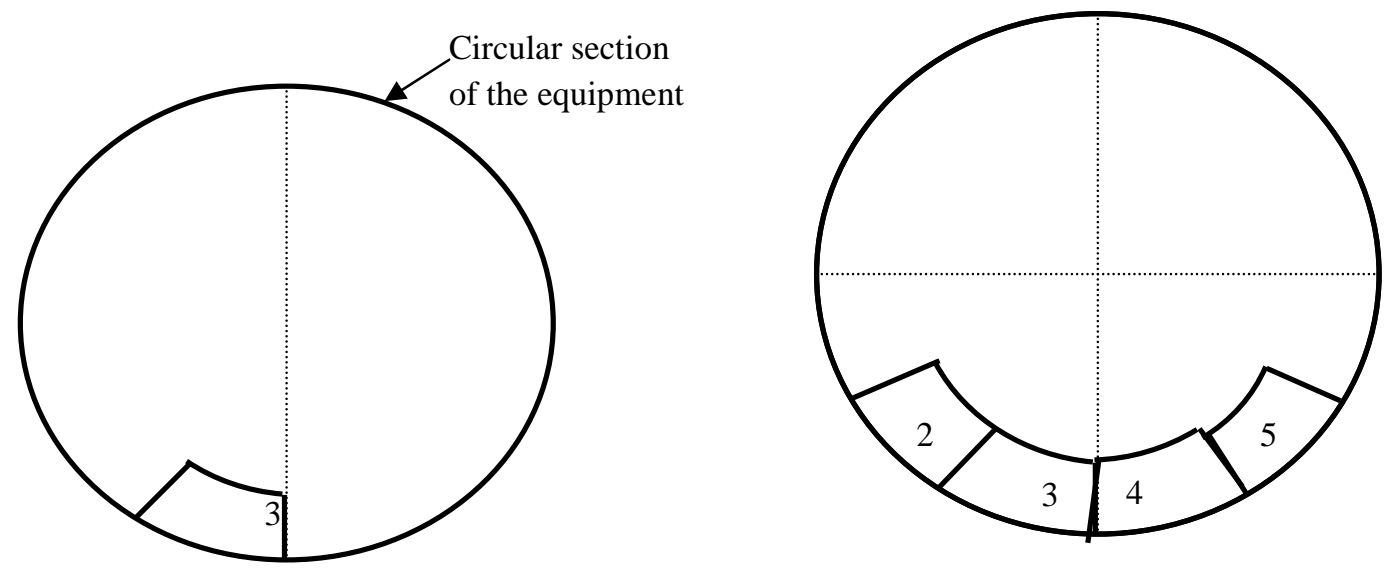

(a) Segment No. 3 fixed

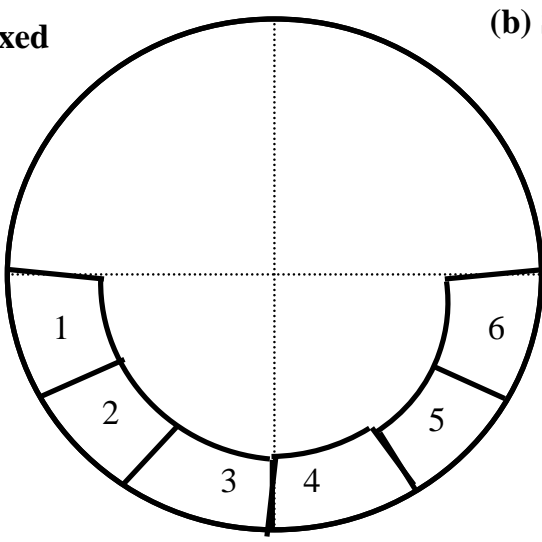

c. The lower segments completed

Fig. 20: Fixing the lower cast segments 
Placing the frame for the fixing of the upper segments

It is important that the frame is properly and accurately put in place (it always need adjustment). The frame must have wooden supports as shown in fig 21 . It is also easy to support the frame with lightweight or high-density refractory bricks and adjusting it with pieces of lum- ber or veneer. Because of weight problems, it is better to support the frame with lightweight bricks instead of high density ones. After first or second attempts, it is easy to place and adjust the frame to facilitate precise fixing of the segments. This is very crucial for obtaining a perfect result, i.e. a precise circular arrangement.

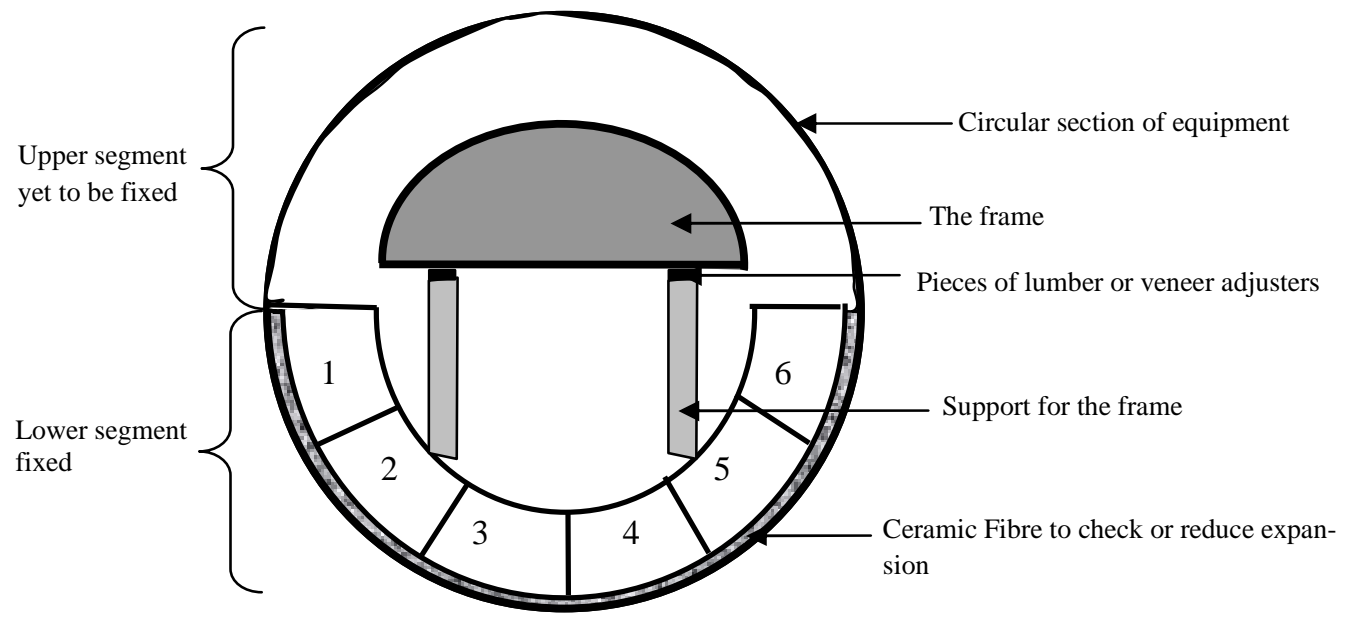

Fig. 21: Frame with wooden supports

Fig. 22 shows a case in which lightweight/high density bricks are used as the support for the frame.

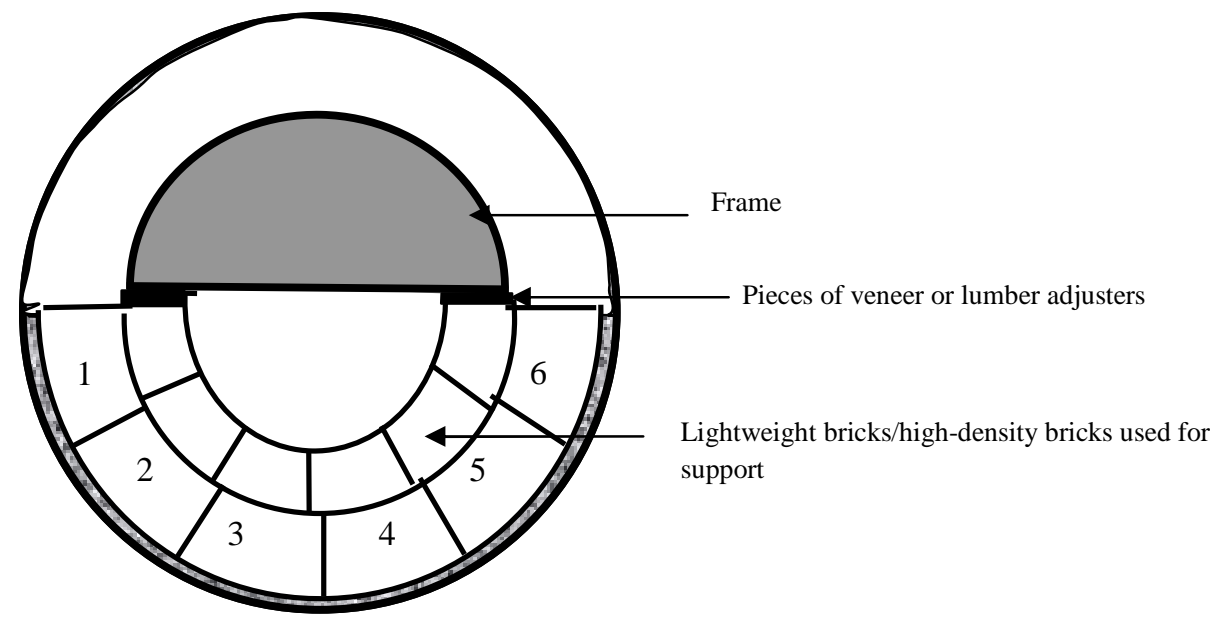

Fig. 22: Frame with bricks support

72 Journal of Science and Technology, Vol. 29, No. 2, Aug., 2009 
The upper segment is then fixed in the following sequence: first, Nos. 12 and 7, then Nos. 11 and 8 then No. 10 and No. 9, i.e. the last one, is fixed after the required adjustments and checks have been done (fig. 23a, 23b). After all the segments have been fixed, and checks have been made, the supports of the frame are gently removed. The frame, which will then be loose, is taken out (fig. 23c).

The difference between the $2^{\text {nd }}$ and $3^{\text {rd }}$ circles is the thickness of the segment. This depends upon the design. Thus, optimum thickness

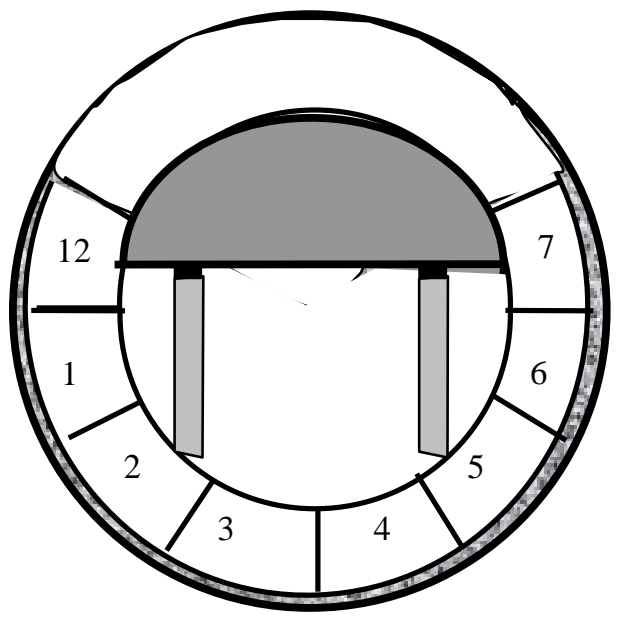

(a) Segments No. 7 and 12 fixed should be employed to protect the metal parts of the equipment and to prevent heat loss. Obviously, the thicker they are the better, because of wear and tear due to the corrosive action of combustion products, (Kingrey, 1960), reacting on the material at the neck. It may be necessary to repeat the cast for the required number of rolls of segment to cover a required length.

The completely cast segments fixed, take the form as shown in figure 24, which shows an arranged cast segments made up of three rolls.

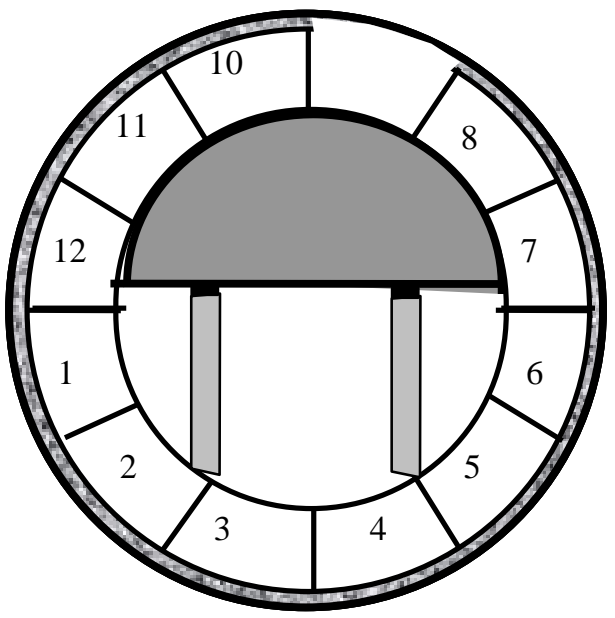

(b) Segments No. 8 and 11 fixed

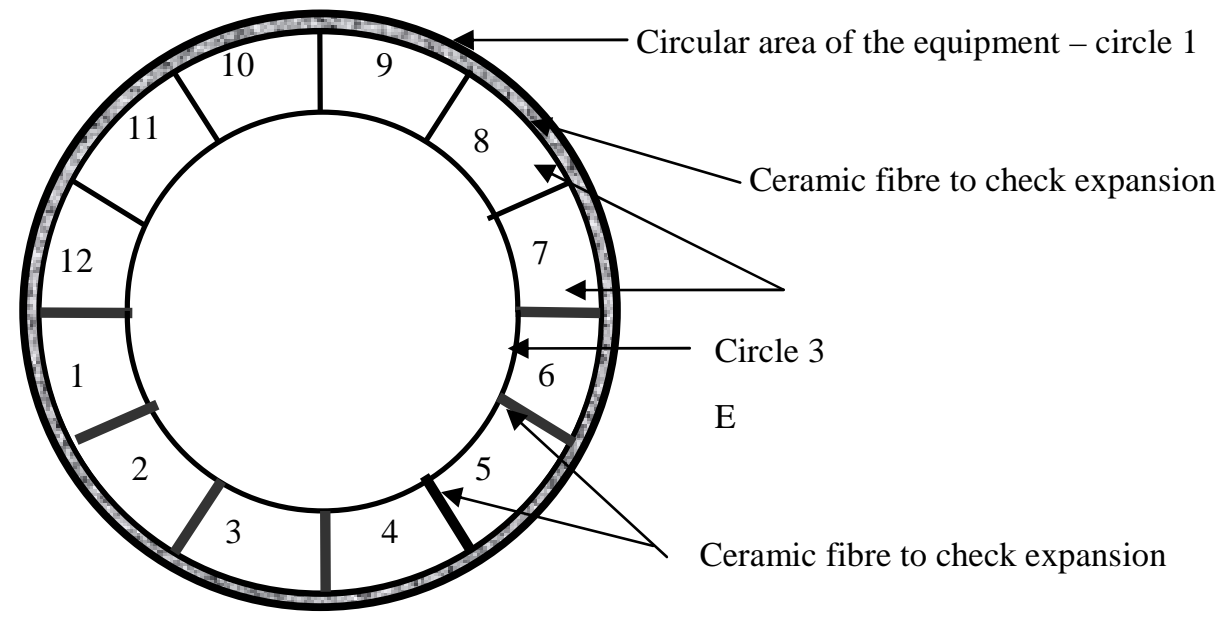

(c) Completed Upper and lower segments after the frame has been removed

Fig. 23: Fixing the upper segments 


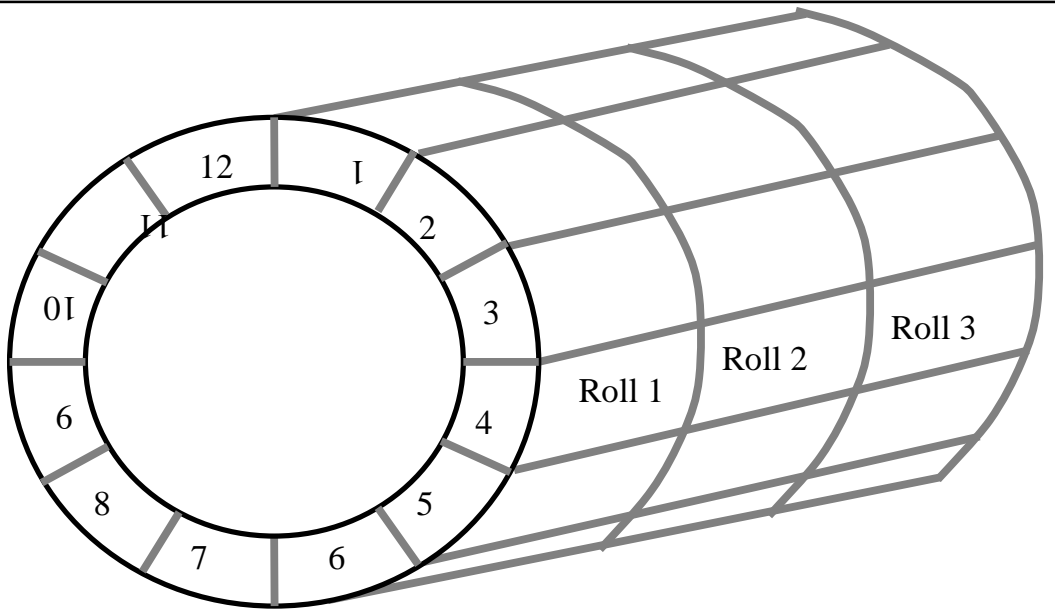

Fig. 24: Three rolls of fixed segments

\section{CONCLUSION}

The design and construction of circular segmented angular shapes is very vital in the effective operation of thermal equipment. Thus, it requires painstaking procedures to attain desired results. Moreover, precision cannot be undermined because negligence leads to loosely fitting circular areas, which in turn leads to fatal industrial accidents. Of equal importance is the selection and mixing of suitable materials for casting the segmented angular shapes.

Therefore, designing and constructing circular areas of thermal equipment requires strict adherence to the principles discussed in this paper.

\section{REFERENCES}

Vincenzini P. (1991), Fundamentals of Ceramic Engineering, Elsevier Science Publishers Limited, U.S.A., p. 56

Anthony L. K., Harry M. S. Jnr. (1991), Boiler Operators Guide, McGraw-Hill Inc, NY, p. 165
Dinsdale A (1986), Pottery Science: Materials, Processes \& Products, Ellis Horwood Ltd, UK, p. 24

Ceramic Research Centre (2000), Information Copy - Production Programme, Krakow City, Poland, p. 5

Kingrey W. D. et al (1960), Introduction to Ceramics, $2^{\text {nd }}$ Edition, John Wiley \& Sons Limited, Canada, pp. 23,46

Nsiah J.K. (2001), A report on the design and construction of the neck of furnace of Boiler No. 3, Omega Wood Processing Company, not published, p. 5

Nsiah J.K. (2000), A report on the rehabilitation of the furnace of Boiler No.1 for electricity generation (co-generation concept), Specialized Timber Products Limited, Kumasi, p. 15

Nsiah J.K. (2000), A report on the rehabilitation of the furnace of Boiler, Western Veneer and Lumber Co. Ltd (W.V.L.C.), Takoradi, 